\title{
Respiratory health effects of opencast coalmining: a cross sectional study of current workers
}

\author{
R G Love, B G Miller, S K Groat, S Hagen, H A Cowie, P P Johnston, P A Hutchison, \\ C A Soutar
}

\begin{abstract}
Objectives-To identify whether there is evidence of pneumoconiosis and other respiratory health effects associated with exposure to respirable mixed dust and quartz in United Kingdom opencast coalmines.
\end{abstract}

Methods-A cross sectional study of current workers (1224 men, 25 women) was carried out at nine large and medium sized opencast sites in England, Scotland, and Wales. To characterise a range of occupational groups within the industry, full shift measurements of personal exposures to respirable dust and quartz were taken. Up to three surveys were carried out at each site, covering all four seasons. For the purposes of comparisons with health indices these groups were further condensed into five broad combined occupational groups. Full sized chest radiographs, respiratory symptoms, occupational history questionnaires, and simple spirometry were used to characterise the respiratory health of the workforce. Logistic or multiple regression techniques were used to examine relations between indices of exposure and respiratory health.

Results-None of the group geometric mean dust concentrations, based on 626 valid dust samples, exceeded $1 \mathrm{mg} \cdot \mathrm{m}^{-3}$, and $99 \%$ of all quartz concentrations were below $0.4 \mathrm{mg} \cdot \mathrm{m}^{-3}$, the current maximum exposure limit. The highest quartz concentrations were experienced by the rock drilling team and drivers of bulldozers (used to move earth and stone from layers of coal). There were clear differences in mean respirable dust and quartz concentrations between occupational groups. These were consistent across the different sites, but depended in part on the day of measurement. The variations between sites were not much greater than between days, suggesting that differences between sites were at least partly explained by differences in conditions at the time of the measurements. The prevalence of radiographic small opacities profusion category $\geqslant 1 / 0$, based on the median of three readings, was $4.4 \%$. Five men had category 2 pneumoconiosis and two men (including one of these five) had progressive massive fibrosis category A. From regression analyses, the relative risk of attaining a profusion of category $\geqslant 0 / 1$ was estimated to be doubled for every 10 years worked in the dustiest, preproduction opencast jobs, after allowing for age, smoking, and site effects. Risk was not associated with time worked in any other occupation within the industry, nor with previous employment in underground mining or other dusty jobs. Symptoms of chronic bronchitis were present in $13 \%$ of the men. Frequency of chronic bronchitis was influenced by years worked in dusty jobs outside opencast mining, but not by time spent in occupations within the industry. Asthmatic symptoms were reported by $5 \%$ of the workforce, close to the mean frequency found in adult men. No positive associations were found between asthma and occupational exposures. Lung function on average was close to predicted values and showed no relation to time worked in opencast occupations.

Conclusions-Frequency of (mostly mild) chest radiographic abnormalities is associated with working in the dustier, preproduction jobs in the industry. Although some of these mild abnormalities may be non-occupational (due to aging or smoking), the association with exposure indicates a small risk of pneumoconiosis in these men, and the need to monitor and control exposures, particularly in the high risk occupations.

(Occup Environ Med 1997;54:416-423)

Keywords: opencast coalmining; occupational dust exposure; respiratory health

In the United Kingdom and other countries opencast (surface or strip) mining is increasingly being used to supply industry's coal requirements because the coal is produced at lower cost. However, relatively little is known of the health effects of long term exposure to airborne dust from opencast workings.

At a typical opencast site, topsoil and subsoil are first removed by scrapers and bulldozers. The rock strata (overburden) which intersperse the coal seams usually consist of mudstones, seat earths, siltstones, and sandstones with occasional shale and ironstone bands. These exposed stone layers which overlie each coal seam are then removed by blasting, carried out by a drilling team of driller, stemmer, and shotfirer. The loosened stone is excavated to just above the underlying coal seam. When the coal has been fully exposed, it is lifted by a coal shovel operator, assisted by labourers who load the coal on to haulage trucks which transport the coal either to a washery for cleaning and 
grading or to a disposal point on or off site, where the coal may be crushed and graded. Each site has its own maintenance team of grader machines for scraping roadways and water bowsers to keep the road surface damp. Fitters, welders, electricians, and other maintenance staff, weighbridge operators, foremen, surveyors, and office staff make up the rest of the workforce.

Given the open nature of such sites it might be expected that the concentrations of any dust generated would be lower than those found in underground coalmines. Indeed a United States study over 20 years ago reported that over $90 \%$ of 66000 dust samples measured at surface coalmines were at or below the United States respirable dust control limit of 2 mg.m. ${ }^{-3}{ }^{1}$ Subsequent United States studies have investigated the prevalence of pneumoconiosis among opencast mine workers. A few cases have been found in men who have worked only above ground ${ }^{3}$ and some men, in particular surface rock drillers, have developed silicosis from exposure to rock dust containing quartz. $^{4}$

There seems to be no published information on the dust conditions experienced by opencast workers on British sites, nor reports of specific effects on respiratory health. To comply with changes in United Kingdom health and safety at work regulations and with regulatory control limits for airborne silica, the industry required information on environmental conditions and the respiratory health of the workers across the industry. Accordingly, a cross sectional study was conducted among current workers at opencast coal sites in England, Scotland, and Wales to determine: (a) the range of exposures to respirable mixed dust and quartz; (b) whether there was evidence of pneumoconiosis (not attributable to previous work in deep coalmines); (c) whether respiratory symptoms and reduced lung function were associated with duration of working in opencast coalmines or in dusty jobs; (d) what dust surveillance procedures should be adopted in the future.

Additional details of this study are available in report form. ${ }^{5}$

\section{Methods}

\section{STRATEGY}

The study was designed as a cross sectional survey of the respiratory health of current opencast coalworkers. Detailed occupational histories were taken during the survey. A linked programme of environmental sampling characterised differences between exposure conditions in different occupations. Occupations were summarised into combined groups, which were used to assess cumulative individual occupational histories in units of years worked.

\section{SELECTION OF SITES}

At the beginning of the study in 1990 there were 54 opencast coal sites in the country employing about 5000 men, mostly contracted workers. The sites selected for the study were drawn from all the main British coalfields: cen- tral Scotland, Tyne and Wear, Cumbria, English midlands, and south Wales. As pneumoconiosis is likely to appear only after at least five years of exposure to airborne dust, six large and medium sized sites were selected which had been in operation for at least five years. Two of the next longest operating sites were added, the first to increase numbers in south Wales, and the second to provide some coverage in north west England. The last site selected was a large recently opened Scottish site, expected to have an operational life of at least 15 years, and which might provide opportunities for later follow up studies.

This selection pattern was intentionally weighted towards longer term sites in an attempt to ensure the inclusion of men with longest exposure. It was also hoped that a proportion of the men studied would have previously worked at other opencast sites.

\section{DUST SAMPLING SURVEYS}

Preliminary visits enabled the identification of the various occupations present at each site. These were subsequently combined into occupational groups, on the basis of similar working and dust conditions, to allow consistent selection and sampling. Detailed dust surveys were based on a sampling strategy which was weighted preferentially towards jobs containing large proportions of the workforce, dustier occupations, and those likely to experience variability of exposure. Every site was visited at least once for a two day survey and four sites had two additional one day surveys separated by several weeks or months, to assess and take account of seasonal variations. Where possible the same employees were resampled during the subsequent surveys.

Up to 60 full shift personal respirable dust samples were collected each day by standard methods with Casella cyclones. ${ }^{6}$ Air at a constant flow rate $(1.9 \mathrm{l} / \mathrm{min})$ was drawn through the cyclones by a belt mounted pump (Casella AFC123 or SKC Aircheck 22443XR). The dust samples, collected on preweighed $37 \mathrm{~mm}$ GLA-5000 filters, were returned to the laboratory for analysis. Weighing was in duplicate to an accuracy of $0.01 \mathrm{mg}$. Quartz content was analysed by Fourier transform infrared spectrophotometry or by $x$ ray diffraction. ${ }^{78}$ Quartz concentrations were detectable to the nearest $0.01 \mathrm{mg} \cdot \mathrm{m}^{-3}$.

\section{MEDICAL SURVEYS}

All employees on the selected sites were invited to attend a medical survey performed in two mobile caravans located at the site. A full size chest radiograph was taken, and a questionnaire of respiratory symptoms and smoking habits was administered by a trained clerk, based on the Medical Research Council (MRC) questionnaire ${ }^{9}$ supplemented by questions about asthmatic symptoms. ${ }^{10}$ Subjects were classified as having asthmatic symptoms if they gave positive answers to a question on chest wheezing or whistling and at least two of the questions on (a) attacks of shortness of breath with wheezing, $(b)$ tightness in the chest 
first thing in the morning, (c) shortness of breath during the day, and $(d)$ being woken at night by an attack of shortness of breath. However, the combination of $(a)$ and (c) alone was not considered to be sufficient owing to their similarity.

Lung function was measured with a bellows spirometer (Vitalograph Limited, model PFT), which was calibrated daily with a 1 litre syringe. Forced expiratory volume in one second $\left(F_{1}\right)$ and forced vital capacity (FVC) were recorded during triplicate forced expiratory manoeuvres, following standard European Community procedures. ${ }^{1 "}$ To identify dusty or otherwise noxious exposures in opencast mining and any previous jobs, a full occupational history was taken by an experienced clerk, on a standard recording form. The jobs were later coded, with the same occupational group scheme as for the dust sampling.

The chest radiographs and other information were assessed for clinical purposes, reports being sent to the individual people and their own doctors if appropriate. Subsequently all $x$ ray films were randomised and classified independently by three physicians experienced in the interpretation of the appearances of pneumoconiosis according to the International Labour Office (ILO) classification. ${ }^{12}$ The profusion classifications of the three readers were summarised by taking the median of the three classifications.

Differences between employees' personal dust and quartz exposures between and within occupational groups were assessed with analysis of variance (ANOVA). The results were used to pool occupational groups into five combined groups, according to the similarity of their exposures. Individual people's occupational histories were summarised as the total times spent in these five groups within the industry and in dusty occupations outside the industry. These times were used as measures of exposure in the analysis of the respiratory health data.

Frequencies of radiographic changes, and of symptoms of chronic bronchitis and asthma, were described in tabular form. The relations between the risks underlying these prevalences and the times in combined occupational groups were analysed by applying logistic regression modelling ${ }^{13}$ to each of the responses. These analyses allowed account to be taken of other factors such as age, smoking habit, and site. The model fitting strategy was, for each response, to fit a baseline model in these factors and their interactions, retaining only significant contributions; and then to investigate whether any of the variables summarising time in combined occupational groups produced a significant improvement in the model fit. Lung function differences were investigated in the same way, with linear regression techniques. ${ }^{14}$

All analyses were carried out with the statistical package Genstat. ${ }^{15}$ Graphs were prepared on a PC with the package Sigmaplot for Windows. ${ }^{16}$

\section{Results}

OCCUPATIONAL HYGIENE SURVEYS

Derivation of occupational groups

Twenty nine occupational groups were derived from the 225 distinct jobs identified, based mainly on the similarity of the work done in these jobs. These groups included drillers, stemmers (who fill the drilled holes), and shotfirers, who constitute the drilling team, excavator operators, stone dumper drivers, bulldozer drivers, haulage drivers, and washery and disposal point operators (only present on three sites).

\section{Respirable mixed dust concentrations}

Six hundred and twenty six dust samples were available for analysis, collected over a period of nearly one year covering all four seasons.

Figure A shows the distributions, on a logarithmic scale, of respirable mixed dust concentrations within each occupational group sampled. This box and whisker plot is a diagrammatic summary of the shape of a distribution, and shows the middle $50 \%$ of the data, from the 25th to the 75th percentile, as a box with a crossbar at the median; the lines, or whiskers, run to the 10 th and 90 th percentiles, and points outside this range are drawn individually. The maximum concentration measured was $20.1 \mathrm{mg} \cdot \mathrm{m}^{-3}$ for a stemmer, a member of the drilling team, yet no group had a geometric mean concentration $>1 \mathrm{mg} \cdot \mathrm{m}^{-3}$ (except for occupational group $Z$, disposal point, office and plant workers, for whom only one sample was available).

The spread of data within each occupational group was roughly symmetric on the logarithmic scale, and an analysis of variance (ANOVA) was performed on the (natural) logarithms of dust concentrations. The results suggested that there were clear differences between occupational groups, which were consistent across the different sites but depended in part on the day of measurement. The variations between sites were not much greater than the variation between days, suggesting that differences between sites were, at least partly, explained by differences in conditions at the time of the visit.

Figure A indicates that drillers, stemmers, shotfirers, and bulldozer drivers had higher mean dust concentrations than most of the other occupational groups. The mean dust concentrations for the occupational groups representing intermediate stages in coal production - that is, stone and coal excavator operators, trimmers, and banksmen (coal labourers), grader (levelling machine) operators, and stone dumper truck drivers-were all lower than those for the drilling team and bulldozer drivers.

\section{Respirable quartz concentrations}

No quartz was detected in 183 out of 626 samples, whereas the highest recorded quartz concentration was $3.1 \mathrm{mg} \cdot \mathrm{m}^{-3}$ for a stone dumper driver (occupational group J). Most of the measured concentrations $(98.6 \%)$ were below $0.4 \mathrm{mg} \cdot \mathrm{m}^{-3}$, although some higher values were found, notably for bulldozer drivers (occupa- 

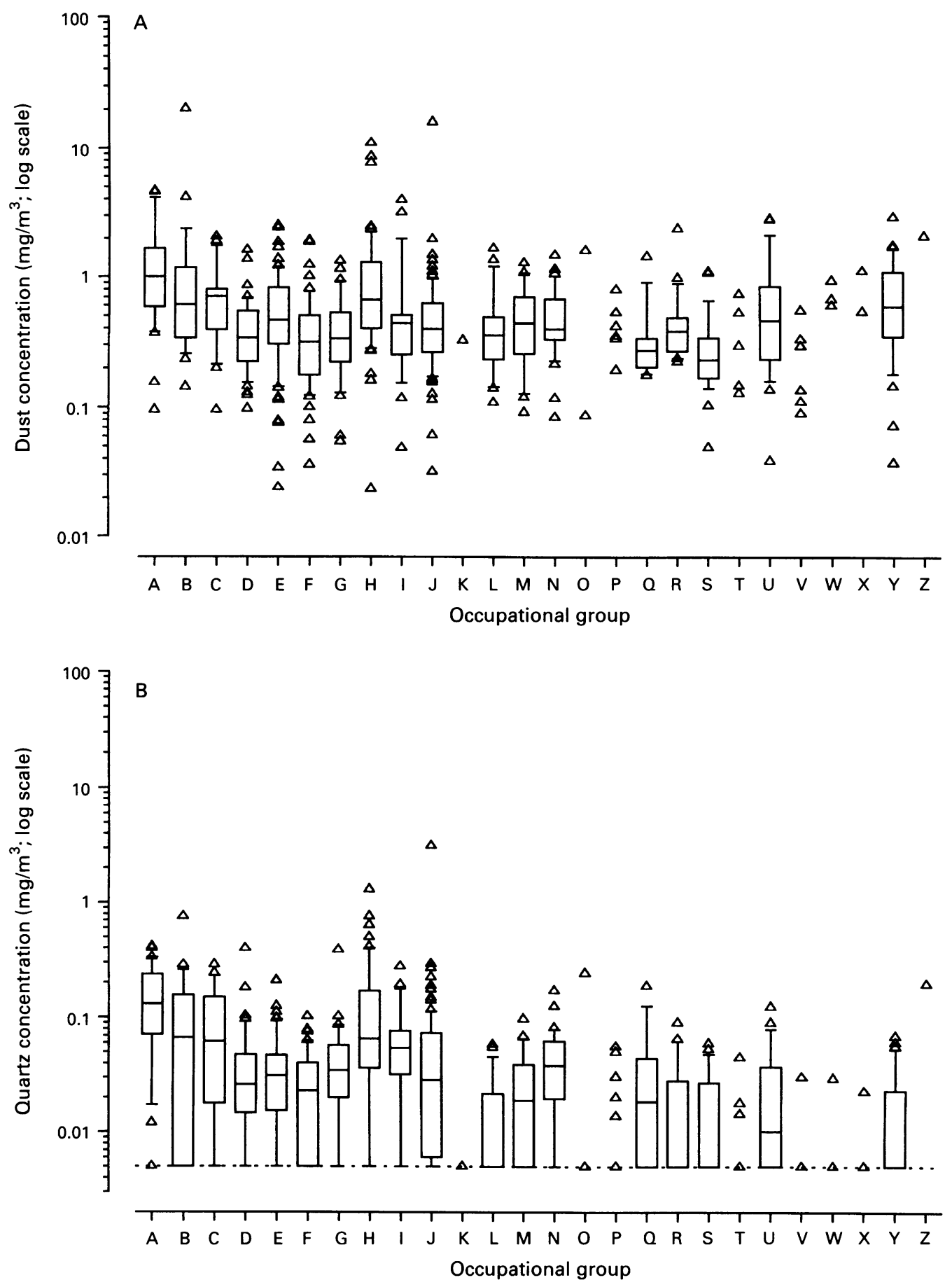

\begin{tabular}{|lll|}
\hline Key to occupational groups: & & \\
A Drillers & J Dumpers stone & S BC site \\
B Stemmers & K Dumpers coal & T BC office/site \\
C Shotfirers & L Coal haulage & U Maintenance workshop \\
D Stone excavators & M Washery & V Office/on site \\
E Coal excavators & N Other occupations/stone & W Disposal point BC \\
F Trimmers/coal labourers & O Other occupations/coal & X Disposal point maintenance \\
G Banksmen & P On site general & Y Disposal point operators \\
H Bulldozers & O Production foremen & Z Disposal point office/plant \\
I Graders & R Maintenance site & \\
\hline
\end{tabular}

Distributions of $(A)$ respirable dust concentrations and (B) respirable quartz concentrations, among occupational groups within opencast mining.

tional group $\mathrm{H}$ ) among whom $45 \%$ of all measurements were $>0.1 \mathrm{mg} \cdot \mathrm{m}^{-3}$. Readings for $44 \%$ of the drilling team (occupational groups $\mathrm{A}, \mathrm{B}$, and $\mathrm{C}$ ) were also higher than this.
Figure B shows box and whisker plots for the distributions of quartz concentrations within each occupational group. Samples below the detection limit were plotted at the value 0.005 
Table 1 Allocation of occupations to combined occupational groups, and summary times spent in these groups $(n=1221)$

\begin{tabular}{llcccc}
\hline $\begin{array}{l}\text { Combined } \\
\text { occupational } \\
\text { group }\end{array}$ & $\begin{array}{l}\text { Occupational groups } \\
\text { included }\end{array}$ & $\begin{array}{l}\text { Mean } \\
(y)\end{array}$ & $\begin{array}{l}\text { Max } \\
(y)\end{array}$ & $\begin{array}{l}\text { Men with } \\
>0 y\end{array}$ & Mean $>0 y$ \\
\hline Preproduction & A, B, C, H & 1.1 & 36.6 & 201 & 6.9 \\
Production & D, E, F, G, I, J & 4.8 & 41.3 & 638 & 9.2 \\
Postproduction & K, L, M, N, O & 0.9 & 25.4 & 279 & 4.1 \\
Office & P, Q, R, S, T, U, V, office, & & & & \\
Disposal point & W, X, Y, Z, DP haulage & 4.1 & 44.8 & 596 & 8.4 \\
$\begin{array}{l}\text { All opencast } \\
\text { External dusty }\end{array}$ & All above & 11.4 & 29.2 & 85 & 5.5 \\
External & & 2.4 & 33.1 & 1221 & 11.4 \\
$\quad$ & & 27.3 & 57.5 & 1221 & 27.3 \\
\hline non-dusty & & & & &
\end{tabular}

Table 2 Distribution of men surveyed by smoking habit and age

\begin{tabular}{lrrrrrr}
\hline \multirow{2}{*}{ Age at survey $(y)$} & & & \\
\cline { 2 - 7 } Smoking habits & $<25$ & $25-34$ & $35-44$ & $45-54$ & $\geqslant 55$ & Total \\
\hline Non-smoker & 48 & 114 & 108 & 72 & 24 & 366 \\
Ex-smoker & 3 & 42 & 86 & 94 & 58 & 283 \\
Current smoker & 42 & 145 & 181 & 134 & 71 & 573 \\
Total & 93 & 301 & 375 & 300 & 153 & 1222 \\
\hline
\end{tabular}

mg. $\mathrm{m}^{-3}$. The general pattern of these plots is similar to that for mixed dust. An ANOVA indicated no evidence that relative differences between concentrations in occupational groups were influenced by the day or site on which they were measured; significant variation between days; little evidence of systematic difference between sites compared with day to day variation; and highly significant differences between occupational groups, before and after adjustment for day of measurement.

The quartz concentrations (fig B) showed a similar picture to those for mixed dust (fig A), the highest mean concentrations being associated with the drilling team and bulldozer drivers. An important difference was the relatively lower position of disposal point operators compared with their mixed dust concentrations. This is almost certainly due to the fact that, although relatively dusty, disposal points only handle coal which has largely been separated from the quartz bearing rock strata.

\section{Derivation of combined occupational groups}

Although there were differences in average concentrations of dust and quartz between occupational groups, the spread of values within these groups was wide and the number of available samples in some groups was small, leading to considerable uncertainty in assigning average concentration values. As there was no available information on past concentrations, it was decided to characterise exposure as time spent in one of a small number of combined occupational groups. With the above analyses and knowledge of the production process, the 29 occupational groups $(26+$ three not sampled: office, canteen, and disposal point haulage) were further condensed, for the purposes of comparison with health indices, into five broad combined occupational groups. These distinguished between ( $a$ ) preproduction (shotfiring, drilling, bulldozer driving); (b) production work with coal and stone; (c) postproduction (dumping, haulage, washery); (d) office, administrative, and managerial; and (e) work at coal disposal points. Both dust and quartz concentrations were highest in group $a$, decreasing to group $d$, whereas group $e$ was relatively dusty but had less quartz in the dust than did the production sites. Time spent by employees included in these surveys was assigned to these five groups and two other combined groups defined as dusty and nondusty work in jobs outside opencast mining. The dusty group included underground mining, quarrying, construction, and asbestos work, whereas the non-dusty group was a catch all group which also included time spent in education, unemployed, etc.

Table 1 summarises the results of these calculations. For 1221 men for whom occupational histories were recorded, the table shows the mean and maximum numbers of years spent in each of the combined occupational groups. As many men had zero time in particular combined groups, table 1 also shows, for each combined group, the number of men with non-zero times, and the mean of those times.

\section{MEDICAL SURVEYS}

Characteristics of study population

The medical survey was attended by 1224 male and 25 female opencast employees, out of a total identified population of 1414 , a response rate of $88 \%$. The mean age of the 1224 men examined was 41 (range 16-65) years, mean height was $1.76(1.52-1.98) \mathrm{m}$ and mean weight was 85.9 (45-180) kg, which is high for men of this average height. Table 2 shows the distribution of men by age and smoking habits. Just under half of the men in the surveys were smokers.

\section{Radiological findings}

Chest radiographs were available for all 1224 men and 25 women. None of the women showed any significant abnormalities, except for one who had some evidence of emphysema. All the subsequent results refer to the 1224 men only. The film quality was judged to be good or acceptable in $84 \%$ and $15 \%$ of cases, respectively.

Table 3 shows the number of films with each median profusion of small opacities (rounded and irregular) by age group. Overall, about $92 \%$ had a median profusion of category $0 / 0$, $4 \%$ had category $0 / 1$, and a further $4 \%$ had category $\geqslant 1 / 0$, including five men with $\geqslant 2 / 1$. There were two films on which two readers only agreed on the presence of large (category A) opacities, on backgrounds of category 1 and 2 small opacities. On the 4 point scale of profusion (0,1,2, and 3) consistency coefficients between readers (defined as the proportion of films for which both readers recorded the same profusion) were between 93\% and $95 \%$.

As expected, the frequency of abnormality increased with age and with smoking habit. For example, $10 \%$ of men over 55 had category $\geqslant 1 / 0$ compared with zero among men younger than 25 . Similarly, $7 \%$ of smokers compared with $1 \%$ of non-smokers had such abnormalities. 
Table 3 Radiological results: distribution of median profusion of small opacities by age group

\begin{tabular}{|c|c|c|c|c|c|c|}
\hline \multirow[b]{2}{*}{$\begin{array}{l}\text { Median } \\
\text { profusion }\end{array}$} & \multicolumn{6}{|c|}{ Age at survey $(y)$} \\
\hline & $\begin{array}{l}<25 \\
n(\%)\end{array}$ & $\begin{array}{l}25-34 \\
n(\%)\end{array}$ & $\begin{array}{l}35-44 \\
n(\%)\end{array}$ & $\begin{array}{l}45-54 \\
n(\%)\end{array}$ & $\begin{array}{l}\geqslant 55 \\
n(\%)\end{array}$ & $\begin{array}{l}\text { Total } \\
n(\%)\end{array}$ \\
\hline $0 / 0$ & $92(99)$ & $292(97)$ & $348(93)$ & $267(88)$ & $124(81)$ & $1123(92)$ \\
\hline $0 / 1$ & $1(1)$ & $3(1)$ & $16(4)$ & $14(5)$ & $13(8)$ & $47(4)$ \\
\hline $1 / 0$ & $0(0)$ & $5(2)$ & $6(2)$ & $13(4)$ & $9(6)$ & $33(3)$ \\
\hline $1 / 1$ & $0(0)$ & $0(0)$ & $3(1)$ & $7(2)$ & $3(2)$ & $13(1)$ \\
\hline $1 / 2$ & $0(0)$ & $0(0)$ & $0(0)$ & $1(0)$ & $2(1)$ & $3(0)$ \\
\hline $2 / 1$ & $0(0)$ & $0(0)$ & $1(0)$ & $0(0)$ & $2(1)$ & $3(0)$ \\
\hline $2 / 2$ & $0(0)$ & $1(0)$ & $0(0)$ & $0(0)$ & $0(0)$ & $1(0)$ \\
\hline $2 / 3$ & $0(0)$ & $0(0)$ & $1(0)$ & $0(0)$ & $0(0)$ & $1(0)$ \\
\hline Total & 93 & 301 & 375 & 302 & 153 & 1224 \\
\hline
\end{tabular}

Table 4 Men with symptoms of chronic bronchitis by smoking habits and age

\begin{tabular}{lllllll}
\hline \multicolumn{7}{l}{ Age at survey $(y)$} \\
\cline { 2 - 7 } Smoking habits & $\begin{array}{l}<25 \\
n(\%)\end{array}$ & $\begin{array}{l}25-34 \\
n(\%)\end{array}$ & $\begin{array}{l}35-44 \\
n(\%)\end{array}$ & $\begin{array}{l}45-54 \\
n(\%)\end{array}$ & $\begin{array}{l}\geqslant 55 \\
n(\%)\end{array}$ & \multicolumn{1}{c}{ Total } \\
\hline $\begin{array}{l}\text { Non-smoker } \\
\text { Ex-smoker }\end{array}$ & $6(13)$ & $4(4)$ & $7(6)$ & $3(4)$ & $1(4)$ & $21(6)$ \\
$\begin{array}{l}\text { Current } \\
\quad \text { smoker }\end{array}$ & $5(12)$ & $4(10)$ & $3(3)$ & $7(7)$ & $3(5)$ & $17(6)$ \\
Total & $11(12)$ & $37(12)$ & $53(14)$ & $37(12)$ & $19(12)$ & $157(13)$
\end{tabular}

$\star$ Unreliable, denominator $<10$

$\%=$ Percentage of total in that group (table 2 ).

Table 5 Lung function variables by smoking habits and age

\begin{tabular}{|c|c|c|c|c|c|c|c|}
\hline \multirow[b]{2}{*}{ Lung function variable } & \multirow[b]{2}{*}{ Smoking habits } & \multicolumn{6}{|c|}{ Age at survey $(y)$} \\
\hline & & $<25$ & $25-34$ & $35-44$ & $45-54$ & $\geqslant 55$ & Total \\
\hline \multirow[t]{4}{*}{$\mathrm{FEV}_{1}$} & Non-smoker & 4.49 & 4.39 & 4.04 & 3.76 & 3.38 & 4.11 \\
\hline & Ex-smoker & 4.78 & 4.38 & 4.08 & 3.61 & 3.08 & 3.77 \\
\hline & smoker & 4.54 & 4.30 & 3.82 & 3.50 & 2.82 & 3.80 \\
\hline & Total & 4.52 & 4.34 & 3.94 & 3.60 & 3.00 & 3.88 \\
\hline \multirow[t]{5}{*}{ FVC } & Non-smoker & 5.42 & 5.38 & 5.06 & 4.79 & 4.37 & 5.11 \\
\hline & Ex-smoker & 5.71 & 5.45 & 5.19 & 4.64 & 4.17 & 4.84 \\
\hline & Current & & & & & & \\
\hline & smoker & 5.49 & 5.39 & 4.97 & 4.67 & 4.05 & 4.93 \\
\hline & Total & 5.46 & 5.39 & 5.04 & 4.69 & 4.14 & 4.96 \\
\hline \multirow{4}{*}{$\mathrm{FEV}_{1} / \mathrm{FVC}(\%)$} & Non-smoker & 83.0 & 81.6 & 79.9 & 78.8 & 77.2 & 80.5 \\
\hline & Ex-smoker & 83.3 & 80.7 & 79.0 & 77.6 & 73.9 & 77.8 \\
\hline & smoker & 82.9 & 80.0 & 76.9 & 75.0 & 69.2 & 76.7 \\
\hline & Total & 83.0 & 80.7 & 78.3 & 76.7 & 72.2 & 78.1 \\
\hline
\end{tabular}

Values are means for groups in table 2.

Table 6 Predicted risks of showing small opacities $\geqslant 1 / 0$ as a function of age, smoking, and number of years worked in preproduction occupations in opencast mining, averaged over all sites

\begin{tabular}{lcrrr}
\hline \multirow{2}{*}{ Age at survey $(y)$} & Smoking habit & \multicolumn{3}{c}{$\begin{array}{l}\text { Years worked in preproduction occupations in opencast } \\
\text { coalmining }\end{array}$} \\
\cline { 3 - 5 } & \multicolumn{1}{l}{0} & \multicolumn{1}{l}{10} & \multicolumn{1}{l}{20} \\
\hline 45 & Non-smoker & $3.6(1.10)$ & $7.3(2.35)$ & $14.2(5.56)$ \\
& Ex-smoker & $4.2(1.33)$ & $8.6(2.65)$ & $16.5(5.98)$ \\
55 & Currentsmoker & $11.0(1.44)$ & $20.4(3.30)$ & $33.9(7.69)$ \\
& Non-smoker & $4.1(1.96)$ & $8.4(3.84)$ & $16.1(7.62)$ \\
& Ex-smoker & $10.9(2.52)$ & $20.3(4.38)$ & $33.8(8.27)$ \\
& Currentsmoker & $23.4(3.21)$ & $37.7(5.02)$ & $53.3(7.96)$ \\
\hline
\end{tabular}

Values are estimated percentage risks (SEs).

\section{Respiratory symptoms}

Table 4 shows the distribution of chronic bronchitis (persistent cough with persistent phlegm) by age and smoking habit at all sites combined. Symptoms of chronic bronchitis were reported by $13 \%$ of the workforce, ranging at different sites from $8 \%$ to $18 \%$. There was no apparent relation with age, but an obvious association with smoking habit, $21 \%$ of smokers reporting symptoms com- pared with $6 \%$ of non-smokers and exsmokers.

Sixty men, just under $5 \%$, were classified as having asthmatic symptoms.

\section{Lung function}

Four men did not complete the lung function tests. Table 5 summarises the results of the remaining 1220 . The maxima of three recorded values of forced expiratory volume in one second $\left(\mathrm{FEV}_{1}\right)$ and forced vital capacity (FVC) have been used in this analysis. Values for $\mathrm{FEV}_{1}$ ranged from 0.8 to 5.91 and averaged 3.9 l. Forced vital capacity was on average 5.0 1, ranging from 2.4 to 7.81 . The derived $\mathrm{FEV}_{1}$ / FVC ratios averaged $78 \%$ (range 35\%-98\%). As expected, all lung function indices declined with age and were worse among smokers.

\section{EXPOSURE-RESPONSE RELATIONS}

\section{Radiological abnormalities}

Logistic regression analyses were used to relate the risk of having a median profusion of small opacities of category $\geqslant 0 / 1$ to times in combined occupational groups, among 1221 men with chest radiographs and relevant data. Comparison of several initial models showed that the risk was significantly affected by age and smoking habit; and that the age effect was steeper in ex-smokers and current smokers than in lifelong non-smokers. Having allowed for these factors, the risk increased with the number of years worked in the dustiest preproduction combined occupational group. Risk was not associated with time worked in any of the other combined occupational groups, nor with time worked previously in underground mining or other dusty employments outside the industry.

The logistic regression coefficient for years in preproduction work, adjusted for age, smoking, age-smoking interaction, and site effects, was estimated at 0.796 (SE 0.0203). Ten years' work in this group of occupations would therefore be predicted to multiply the odds (of showing small opacities $\geqslant 0 / 1$ ) by a factor of $\exp ^{0.796}=2.2 \quad(95 \%$ confidence interval $(95 \%$ CI) 1.4 to 3.3). Table 6 shows examples of the risks predicted by the regression model, for two different ages, for each of the smoking groups, and an occupational history including no work in the preproduction group, and 10 or 20 years' work in that group.

Attempts to analyse responses representing higher categories of profusion of small opacities $(\geqslant 1 / 0)$ encountered convergence problems due to the few positive responses, and are not reported here.

\section{Respiratory symptoms}

Logistic regression analyses were also carried out on the self reported respiratory symptoms. The risk of reporting symptoms of chronic bronchitis was related principally to current smoking habit, and was not related to time spent in any of the opencast combined occupational groups. However, there was some evidence that the risk of symptoms of chronic bronchitis increased with increasing time previously worked in dusty jobs outside the 
industry. The relative odds for 10 years employment in such jobs was 1.4 (95\% CI 1.06 to 1.9 ).

A similar analysis for symptoms of asthma, the presence of which was strongly but not completely associated with that of chronic bronchitis, showed no strong evidence of any relations with any exposure index, and no effect of smoking habit.

\section{Lung function}

Measurements of lung function - that is, $\mathrm{FEV}_{1}$, FVC, and their ratio-were analysed with linear regression models, and showed the expected relations with height, age, and smoking habits. Neither FEV 1 nor FVC, nor their ratio, showed any significant relation with years worked in dusty jobs within or outside opencast mining.

\section{Discussion}

Opencast coalmining in many respects bears a closer resemblance to other surface extractive industries, such as quarrying, than it does to underground coalmining. Most of these activities occur in the open air, where the airborne dust can disperse widely around, and on some occasions outside, the site. It might, therefore, be expected that the mean dust concentrations in the vicinity of workers would be substantially lower than in underground mining even before dust suppression is applied. This is borne out by our measurement of personal respirable dust concentrations during 17 dust surveys at nine sites, of which only nine out of 626 exceeded 4 mg.m ${ }^{-3}$.

These surveys took place during all seasons of the year and during various weather conditions, so they can be considered to be representative of conditions in the industry as a whole. However, although there were variations in dust concentrations on a given site between different survey dates, these resulted more from natural variation on the particular days of sampling than as a result of systematic differences between sites. Subsequent analysis allowed consistent differences in dust concentrations between groups of jobs to be identified.

The population studied were all current employees. It is therefore possible that the effects found are subject to a degree of selection bias. However, there is no evidence, even anecdotal, of wholesale migration out of the opencast mining industry on health grounds, and we think that the size of any such bias is likely to be small.

Previous studies of dust and quartz concentrations in opencast coalmining ${ }^{17}{ }^{18}$ have indicated broadly similar results to ours. Our findings indicate that the estimated (geometric) mean respirable dust concentrations in all but one of the occupational groups were generally low and mostly well below the current control limit for underground mines. The highest mixed dust and quartz values were found among drillers, stemmers, shotfirers, and bulldozer drivers, among whom the measured quartz concentrations were $\geqslant 0.1 \mathrm{mg} \cdot \mathrm{m}^{-3}$ on $44 \%$ of occasions on average. It is also notable that disposal point samples, although indicating relatively high dust concentrations, had much lower amounts of quartz present. This would be consistent with a part of the process in which cleaned coal is handled before despatch from the site.

There was an encouragingly high response rate overall to the medical surveys. Men not employed directly by British Coal or the contractors on the site-such as employees from a neighbouring disposal point-were excluded from this part of the study as well as from the dust surveys. However, we have no reason to think that particular groups of employees were systematically excluded. The results of these surveys should therefore be representative of the current workforce in the industry. Although drilling teams prospecting for sources of coal for opencast extraction were not included in this survey, a group of prospecting drillers, geologists, and other support staff have had recent $x$ ray films taken and were found to have a frequency of radiological abnormality within the range of that found among opencast miners.

The frequency of category $\geqslant 1 / 0$ radiological abnormality found in this study $(4.4 \%)$ is similar to the results of studies of United States opencast mineworkers, among whom about $4 \%$ were found to have similar radiological abnormalities..$^{2419}$ It is also similar to the frequency of radiological abnormality found among hard rock quarry workers $(4.7 \%)^{20}$ compared with a frequency of $2.8 \%$ in a group of workers not exposed to dust (post office and telecommunications). ${ }^{21}$ (Note that our selection of opencast sites was intentionally weighted towards longer operating sites where occupational health effects might be expected to be more apparent.) As small radiographic opacities may result from aging or smoking, as well as dust exposure, we allowed for age, smoking, and site differences. We have shown that there is still a strong effect of years worked in the dustiest opencast jobs, indicating the role of occupation in causing this radiological abnormality. Although this is mostly at a relatively low category of profusion, five cases had moderately severe profusions, probably representing pneumoconiosis (category 2) and two men, including one with category 2 , had progressive massive fibrosis, the severe form. One of these men gave a history of being treated for tuberculosis, a well known complication of silicosis.

The proportion of opencast workers reporting symptoms of chronic bronchitis (13\%) was considerably less than that found in our most recent study of underground coalminers (22\%) but slightly higher than in a workforce not exposed to dust (9\%) drawn from a similar social group. ${ }^{21}$ The frequency with which asthmatic symptoms occurred in this population $(5 \%)$ was similar to reported frequencies $(5 \%$ to $8 \%$ ) occurring in the general adult population..$^{22-24}$ The lack of a positive association of asthma with any index of dust exposure suggests that the dust is unlikely to cause asthma in workers on opencast sites. This is consistent with the non-allergenic 
nature of mineral dust, although high concentrations of dust could presumably exacerbate pre-existing asthma.

Deficits of lung function, associated with increasing cumulative dust exposure, have previously been reported among underground coalminers in the United Kingdom. ${ }^{25-27} \mathrm{Re}$ ports from the United States suggest that such deficits have also been found in drillers from opencast mines but not among workers in coal cleaning plants. $^{18}$ We have not found any general significant relations between either $\mathrm{FEV}_{1}$ or FVC and any index of dust exposure in the opencast industry.

The evidence from this and previous studies of opencast mineworkers suggests that there is a small risk of pneumoconiosis associated with working for many years in the dustiest jobs in opencast mining, particularly the drilling team and bulldozer drivers. As their exposure is principally to dust from overburden that contains silica rather than to coal, and as the exposures to respirable dust are far lower than the exposure to coalmine dust associated with coalworkers' pneumoconiosis, it is likely that the pneumoconiosis represents silicosis. Banks et al found cases of silicosis in their United States study of surface drillers. ${ }^{4}$

We therefore conclude that exposure to airborne mixed respirable dust, particularly in the dustiest preproduction parts of the industry, can give rise to a small risk of radiological abnormalities, consistent with the characteristics of pneumoconiosis, probably silicosis. The dust conditions are not sufficient to cause notably reduced lung function or increased frequency of chronic bronchitis, nor are they associated positively with symptoms of asthma. However, the results point to a need for continuing vigilance to keep dust exposures low, particularly in those occupations at highest risk.

We have recommended: ${ }^{5}$ increased measures to control dust and quartz concentrations in the dustier jobs; an annual programme of monitoring of airborne dust and quartz in the high risk occupations; radiographic surveillance for process workers, every three years; and follow up or prospective studies to provide more data from which better to assess the relative risks of different exposures to quartz and the effects of tighter controls on dust.

We gratefully acknowledge the support of British Coal Opencast, and thank the following: numerous colleagues at the Institute of Occupational Medicine; Mrs M Russell and Dr MA Rickards, previously of British Coal Radiological Services, for radiographic services and clinical assessments respectively; Professor A Seaton, Dr M Rickards, Dr J Bennett for epidemiological classification of radiographs; the many contractors, subcontractors, British Coal Opencast personnel and all participants for their cooperation; and Professor Seaton and Dr M Jacobsen, formerly of the IOM, for originally helping to set up the study.

1 Parobeck PS, Tomb TF. Respirable dust levels - surface work areas of underground coalmines and surface coalmines. Work Environ Health 1974;11:43-8.

2 Fairman RP, O'Brien RJ, Swecker S, Amandus HE, Shoub EP. Respiratory status of surface coalminers in the United States. Arch Environ Health 1977;32:211-5.

3 Amandus HE, Hanke W, Kullman G, Reger RB. A re-evaluation of radiological evidence from a study of US re-evaluation of radiological evidence from a study of US

4 Banks DE, Bauer MA, Castellan RM, Lapp NL. Silicosis in Banks DE, Bauer MA, Castellan RM, Lapp NL. Silc
surface coalmine drillers. Thorax 1983;38:275-8.

5 Love RG, Miller BG, Beattie J, Cowie HA, Groat S, Hagen $\mathrm{S}$, et al. A cross-sectional epidemiological study of the respiratory health and exposure to airborne dust and quartz of current workers in opencast coalmines. Edinburgh: Institute of Occupational Medicine, 1992. (IOM Report TM/92/03.)

6 Health and Safety Executive. General methods for the gravimetric determination of respirable and total dust. London: Health and Safety Executive, 1983. (MDHS 14.)

7 Health and Safety Executive. Quartz in respirable airborne dusts. Laboratory method using infra-red spectroscopy (direct dusts. Laboratory method using infra-red spectroscopy (direct
method). London: Health and Safety Executive, 1987. method). Lon

8 Health and Safety Executive. Quartz in respirable airborne dusts. Laboratory method using $x$-ray diffraction (direct method). London: Health and Safety Executive, 1988. (MDHS 51/2.)

9 Medical Research Council. Questionnaire on respiratory symptoms. London: MRC, 1986.

10 Burney $P$, Chinn $S$. Developing a new questionnaire for measuring the prevalence and distribution of asthma. Chest 1987;91 (suppl):79s-83s.

11 Quanjer PH. Standardized lung function testing. Bulletin Européan de Physiopathologie Respiratoire 1983;(suppl 5).

12 International Labour Office. Guidelines for the use of ILO international classification of radiographs of pneumoconiosis. Geneva: ILO, 1980. (Occupational Safety and Health Series, No $22(\operatorname{Rev} 80)$.)

13 Collett D. Modelling binary data. London: Chapman and Hall, 1981.

14 Draper NR, Smith H. Applied regression analysis, 2nd ed. New York: John Wiley, 1981.

15 Genstat 5 Committee. Genstat 5 reference manual. Oxford: Clarendon Press, 1987.

16 Kuo J, Fox E. Sigmaplot for windows users manual. Erkrath: Jandel Scientific, 1993.

17 Amandus HE, Piacitelli GM. Dust exposures at US surface coalmines in 1982-3. Arch Environ Health 1987;42:374 81.

18 Piacitelli GM, Amandus HE, Diffenbach A. Respirable dust exposures in US surface coalmines (1982-6). Arch Environ Health 1990;45:202-9.

19 Amandus HE, Petersen MR, Richards TB. Health status of anthracite surface coal miners. Arch Environ Health $1989 ; 44: 75-81$.

20 Agius RM, Love RG, Davies LST, Hutchison PA, Cherrie JW, Robertson A, et al. Studies of the epidemiology of respiratory health and of dust exposure in hard rock quarry workers and ex-workers. Edinburgh: Institute of Occupational Medicine, 1992. (IOM Report TM/92/10.)

21 Lloyd MH, Gauld SJ, Soutar CA. Respiratory ill health among coalminers and telecommunications workers in among coalminers and telecommunication

22 Dodge RR, Burrows B. The prevalence and incidence of asthma and asthma-like symptoms in a general population sample. Am Rev Respir Dis 1980;122:567-75.

23 Turner-Warwick $M$. Occupational lung diseases: the scope of the problem. In: Weill H, Turner-Warwick M, eds. Occupational lung diseases: research approaches and methods. New York: Marcel Dekker, 1981:1-10.

24 Love RG, Murdoch RM, Campbell SJ, Soutar CA. Epidemiological study of the relations between asthma and occupation: pilot study of a postal questionnaire. Edinburgh: Institute of Occupational Medicine 1990. (IOM Report TM/90/04.)

25 Love RG, Miller BG. Longitudinal study of lung function in coalminers. Thorax 1982;37:193-7.

26 Soutar CA, Hurley JF. Relation between dust exposure and lung function in miners and ex-miners. Br $\mathcal{F}$ Ind Med 1986; 43:307-20.

27 Maclaren WM, Miller BG, Hurley JF, Love RG. Reference values for lung function decline in working coalminers. Edinburgh: Institute of Occupational Medicine, 1994. (IOM Report TM/94/08.) 


\section{NOTICES}

Disability-One Year On. 1 October 1997. Edinburgh, Scotland.

By the time that this conference, organised by the Scottish Group of the Society of Occupational Medicine, opens, the Disability Discrimination Act will have been on the statute book for almost a year. It has been the biggest legislative item to effect people with disabilities and those who have dealings with them, either as providers of services or employers, since the Disabled Persons (Employment) Acts of 1944 and 1958. It has not been without controversy, and does not please everyone. None the less, to achieve the aims of the spirit of the act-a fair crack of the whip for those with disabilities-people have to work together and do something. People with disabilities have a hard time-we all know that-but attenders at this meeting will leave with positive ideas on how to successfully integrate people with disabilities into the workplace. In association with the Department of Public Health Sciences, University of Edinburgh, and the Scottish Occupational Health Nurses Forum, the Group offers this event, beginning at about $10 \mathrm{am}$, lasting all day, and with exhibition. Contact: Dr C J Kalman, Occupational Health Department, Scottish Nuclear PLC, East Kilbride, Scotland. Tel 01355262000.

\section{Charting the Way Ahead for Health at} Work. 29 September 1997. London.

The Royal College of Physicians, London. This conference, organised by the British Occupational Health Research Foundation and the Faculty of Occupational Medicine, has three sessions titled:

Setting the scene;

Priorities for the future;

Research in progress and in prospect.

Further information from: British Occupational Health Research Foundation, 9 Millbank, London SW1P 3JF. Tel: 0171-798 5869; 0171-7985894.

\section{BOOK REVIEW}

\section{Book review editor: $\mathrm{R}$ L Maynard}

If you wish to order, or require further information regarding the titles reviewed here, please write or telephone the BMJ Bookshop, PO Box 295, London WX1H 9TE. Tel: 0171 383 6244. Fax: 0171383 6662. Books are supplied post free in the UK and for British Forces Posted Overseas addresses. Overseas customers should add $15 \%$ for postage and packing. Payment can be made by cheque in sterling drawn on a UK bank, or by credit card (MasterCard, VISA, or American Express) stating card number, expiry data, and your full name. (The price and availability are occasionally subject to revision by the Publishers.)

Modern Industrial Hygiene, Vol 1. Author: JIMMY L PERKINS. (Pp 840; price $£ 37.50)$ 1997. New York: Van Nostrand Reinhold. ISBN: 0-442-02105-4.

This is the first of four books covering the field of industrial hygiene. Two volumes deal with chemical hazards, and one each with physical and biological hazards. There is no specific volume for psychosocial hazards, and perhaps this is an area of occupational health that lies outside the scope of modern industrial hygiene. Volume 1 focuses on recognition and evaluation of chemical hazards; control is left to the second volume. The author devotes the first two chapters to discussing what is an industrial hygienist and how industrial hygiene fits into occupational health, with a historical account of the development of the discipline. The layout is very comprehensive, and my impression is that considerable effort has gone into producing what ought to be a standard reference book for occupational health professionals.

In the material provided, there is a bias towards United States legislation, organisations, and approach (readers can refer to the book for a description of acronyms such as OSHA, TOSCA, NIOSH, etc). The author rightly explains the difficulty in keeping up with changes in the United States, let alone trying to deal with the situation in other countries. There is a nod in the direction of
non-United States references in the sources of information section. The British fournal of Industrial Medicine is mentioned, but as this is a 1997 book, it should rightly be Occupational and Environmental Medicine. The Scandinavian Journal of Occupational Health is probably the Scandinavian fournal of Work, Environment and Health. These niggles aside, the book is rich with facts and well illustrated with photographs of hygiene equipmentmore than enough to aid postgraduate occupational health students in their revision for their professional exams. There are good descriptions of pumps, detector tubes, direct reading instruments, and other industrial hygiene devices, complete with how they should be calibrated and used, right down to the details of what kind of charcoal is used for absorbing vapours. There is a useful list of 11 questions to ask when choosing a laboratory for analysing industrial hygiene samples. Many of these questions would apply to use of a laboratory for analysing other samples such as microbiological analysis or biological monitoring samples. Another useful and interesting chapter describes common industrial processes and exposure to chemical hazards from these processes. This chapter includes electroplating, machining, plastics processing, and welding, to name a few examples. My personal favourite is the series of study questions at the end of each chapter. Some of them are difficult, but answers are provided at the end of the book. If you know the difference between Henry's law, Graham's law, Raoult's law, Fick's law, and Stokes' law, then maybe you should have written the book. These are all covered in this first volume.

My verdict: a most useful book on industrial hygiene. If this volume is anything to go by, the other three should be just as informative and enjoyable.

TAR-CHING AW

\section{CORRECTION}

Respiratory health effects of opencast coalmining: a cross sectional study of current workers by RG LOVE, BG MILLER, SK GROAT, S HAGEN, HA COWIE, PP JOHNSTON, PA HUTCHISON, CA SOUTAR (1997;54:416-23).

Page 421, The first sentence of the second paragraph of the section Radiological abnormalities should read: The logistic regression coefficient for years in preproduction work, adjusted for age, smoking, age-smoking interaction, and site effects, was estimated at 0.0796 (SE 0.0203); not 0.796 (SE 0.0203). 